Paul Bowman

\title{
Mindfulness and Madness in Martial Arts Philosophy
}

\begin{abstract}
This paper derives from a lecture given at a festival of philosophy in Leuven in 2017. In line with the conference theme, it sought to connect 'East Asian Philosophy' with the Dutch word 'rust', and in so doing it uncovers surprising connections between mindfulness and madness.
\end{abstract}

\section{Contact}

Professor Paul Bowman, PhD

Cardiff University

BowmanP@cardiff.ac.uk 
In order to broach the theme of mindfulness and madness in martial arts philosophy, I would first like to make the perhaps unexpected move of seeking to connect the theme of 'Chinese philosophy' with the Dutch word 'rust'. To readers unfamiliar with this Dutch word, such a combination may seem odd or eccentric. However, it should be remembered that what may seem bizarre in one context may feel natural, obvious, inevitable or even necessary in another. In other words, just because the attempt to express ideas of Chinese philosophy or Chinese martial arts in terms of a specifically Dutch term may seem gratuitous or inexplicable in many contexts, in the Netherlands, such an act could be regarded as anything from totally apt to effectively inescapable.

Of course, full disclosure of all of my reasons for doing this would have to include mentioning the fact that I was invited to speak about martial arts and Eastern philosophy at a festival of philosophy in Leuven, a festival whose overarching theme was precisely this Dutch word, 'rust'. Leuven was a city that I had long wanted to visit - not least because it is the place in which the wonderfully subversive educator Joseph Jacotot (1770-1840) famously came up with his conviction that people can teach what they don't actually know, and that learners do not really need teachers (Rancière 1991). This was helpful for me because I am not a philosopher, my knowledge of Eastern philosophy is woefully general, and I don't speak Dutch. In fact, the first time I heard about the Dutch word 'rust' was when I was invited to Leuven to speak about it.

Given my obvious lack of qualifications to speak about any of these things, some may regard my acceptance of the invitation to be the height of arrogance. However, given my interest in the anarchic ideas of Joseph Jacotot (and latterly his key interlocutor, Jacques Rancière), accepting the invitation qua challenge seemed appropriate. For, if Jacotot was right to argue that teachers can teach things they don't actually know, then all could be well. By the same token, even if not, according to the rest of that same argument, no one really needed me to teach them anything anyway, and they would definitely still learn something.

To begin: as already mentioned, one of the first things relevant to this discussion that I didn't know in advance was the Dutch word rust. So, I needed to look it up. To do so, I duly turned to the $O E D$, which presented me with a phenomenal amount of etymological information, ${ }^{1}$ most of which I could do absolutely nothing with. So, next I simply googled the

\section{Brit. /r^st/ \\ U.S. /rəst/}

Forms: a. $\mathrm{OE}-15$ rost, $\mathrm{OE}-$ rust, $M E$ roste, $M E-15$ ruste.

Origin: A word inherited from Germanic.

Etymology: Cognate with West Frisian rust, roast, Middle Dutch roest, rost (Dutch roest ), Old Saxon rost (Middle Low German rost, rust ), Old High German rost (Middle High German rost, German Rost ), Faroese rustur , Norwegian rust, Old Swedish rost, rust, ruste, roster (Swedish rost ), early modern Danish rost, rust , røst (Danish rust), probably < a suffixed (or perhaps compounded) form of an ablaut variant of the same IndoEuropean base as RED adj. and $n$. (compare RUD $n .^{1}$ probably showing the same ablaut grade), hence with reference originally to the red colour of rust. Use in sense A. 6 is also widespread among the other Germanic languages. Different formations also probably ultimately < the same Indo-European base as RED adj. and $n$. and also with the meaning 'rust' are shown by Old Icelandic ryð, ryðr, Old High German rosomo, and, outside the Germanic languages, by Lithuanian rūdys, Old Church Slavonic rŭžda (Old Russian r"ža, rža, Russian rža), classical Latin rōbīgō, rūbīgō.

In Old English a strong masculine or neuter $a$-stem. The Old Saxon and Old High German forms (and likewise Middle Dutch rost ) show the expected West Germanic lowering of * $u>{ }^{*} O$ in an $a$-stem formation *rusta- , which is probably also shown by the (rare) early Old English form rost . The B. forms suggest the existence of a by-form 
word, using search terms like 'Dutch word rust' and 'meaning of Dutch word rust'. Some cross-referencing across different sites reassured me that I was finding reliable information, so I felt I was learning more and more about the word, its usage and meanings. One site told me this:

English words for the Dutch word rust

\section{calmness dead ease half time hush imperturbability intermission let-up lie-off pause peace placidity quiescence quiescency quiet quietness quietude recess re- posal repose rest silence tranquility tranquillity wait at ease ${ }^{2}$}

Another site concurred with all of this, telling me that 'rust' means 'break; calm; ease; halftime; pause; peace; placidity; quiescence; quiescency; quiet; quietness; quietude; recumbency; repose; respite; rest; surcease; tranquillity'. ${ }^{3}$ And it also told me how to use the word, in the imperative, as a command: rust!, which means 'stand at ease!'

At that point I felt I could rest easy (or rust easy), safe in the knowledge that I had just become a bit of an expert on the word, even though I didn't have a teacher, and couldn't otherwise speak Dutch. Even better, I could now see an immediate or obvious potential connection between 'rust', 'Eastern philosophy' and martial arts. For, as is commonly believed, there has long been a connection made between East Asian martial arts and supposedly Taoist or Zen Buddhist ideas of calmness and tranquillity. Of course, much of this connection is based on myths (and mainly media myths, at that (Frank 2006; Wile 2015; Bowman 2017)). Nor does everything covered in the meanings of 'rust' that could apply to martial arts necessarily have to refer to either Taoism, Zen or Buddhism. Anyone who has ever done any wrestling or groundfighting learns quickly not to panic or tense up when rolling around on the ground with an opponent who is trying to choke, lock, pin, hold or strangle you out. Beginners tense up to high heaven and panic and expend enormous amounts of energy. The more advanced you become, the more you stay calm, relaxed, tranquil, and the more you can (ultimately) flow.

In such martial arts, the ability to flow is key: not to get knotted up wherever the opponent is trying to take control or issue force; but rather to flow (or crash) around or through a problem and turn the tables. If we are face to face and you push forward into me and I push forward into you, then whoever is stronger will prevail. But if you push forward and I flow around that, then you end up pushing nothing and I should be able to capitalize on that - to the extent that I can flow. And the extent to which I can flow is the extent to which I am relaxed and calm in a very particular way.

with a long vowel in Old English, although both the date and the mechanism by which such a form arose are unclear. The modern form rust with short vowel could then result from this by-form, with shortening in late Old English before a consonant cluster. However, a form with short $u$ could also have existed earlier, since exceptions to the West Germanic lowering of * $u>{ }^{*} o$ before a back vowel are not uncommon in Old English. The vowel of Middle Dutch, Dutch roest is not satisfactorily explained. (The modern West Frisian form roast shows the expected development from West Germanic short * $u$ in this position; the West Frisian form rust probably also ultimately reflects a development from *rusta-, rather than from a form with a long vowel.)

For evidence of currency of forms showing the (diphthongal) reflex of a long vowel in English regional (northern) use in the 20th cent. see H. Orton Phonology of a South Durham Dialect (1933) §133.

2 http://www.wordhippo.com/what-is/the-meaning-of/dutch-word-rust.html

3 http: / / www. majstro.com/Web/Majstro/bdict.php?gebrTaal=eng\&bronTaal=dut\&doelTaal=eng\&teVertalen=rust

Bowman, P. (2019). Mindfulness and Madness in Martial Arts Philosophy.

Journal of Martial Arts Research, 2 (1).

DOI: 10.15495/ojs_25678221_21_93 | j-o-mar.com 
As Bruce Lee famously put it, 'be like water', because water can flow and it can crash, it can push and it can pull, but you can't grab it with your fist and if you try to punch it you won't hurt it; it fills any space and passes through any gap, but try to wrestle it and you end up wrestling nothing. (It's a wonderful image. But I would add that even water can only be like water when it is not too hot and not too cold. If it's too hot it becomes vapour or steam, and loses something; and when it's too cold it becomes frozen, tense, rigid and brittle.) Perhaps in all martial arts, one or another form of relaxation is the thing; one or another kind of calmness of mind, acuity of consciousness, clarity of intent, fluidity of body. Each martial art has a different way of being relaxed and in flow, a different ideal that practitioners aspire to. The boxer, kickboxer, Thai boxer, karateka, escrimador or kung fu hard stylist have distinct kinds of ways of flowing - combining striking techniques fluidly, rolling with the punches, capitalising on the gaps and opportunities provided by the other, smashing their way through. The judoka, wrestler and jujitsuka rely on the same principle, although it is very differently actualised.

But the premise, aim and ideal is always calm relaxation, if not simply tranquillity.

Tranquillity is normally associated with the 'most internal' of what they (problematically) call the 'internal' martial arts. The ultimate example is taiji (tai chi, or taijiquan), of course. But many anecdotes from many different martial arts styles convey a sense that the highestlevel practitioners of almost any martial art can convey an air of tranquillity when fighting.

\section{Training Rust}

Still, taiji is certainly a notable case. For, in its modern forms, almost all of its training is designed to train relaxation, calmness and a great deal of what is conveyed by the Dutch word rust. Advanced-level taiji practitioners spar like they are strolling, not running, charging or dancing. It's like they are simply carrying out a task that they have done countless times and it's simply second nature. So, watching them deal with opponents is like watching someone steering a boat, flying a kite, mowing a lawn, folding laundry, or rolling up a cable; or a fisherman casting and reeling. It's a very simple, very unglamorous, very relaxed, very natural, yet very skilful thing.

I have occasionally had the pleasure of being the one who is folding and felling opponents like a laundry worker folding and flattening out sheets. And when you are in that zone, that state of flow, it is very much like that - just something that you are doing; pleasurable, but natural - no real effort; no real striving, planning, pursuing: just feeling and doing. Of course, I have much more often been on the receiving end, against someone who wants to treat me like some laundry that needs to be straightened and folded and flattened out. A popular martial art saying is 'you either win or you learn'. And I have done a lot of learning.

And not just in taiji. I have been folded and flattened in many different martial arts styles over many years. Occasionally it has been me doing the folding and flattening, and that is always a very nice treat. But none of the other kinds of sparring that I know involve activities that are as necessarily calm and tranquil as taiji. Doubtless, this is connected with the unique and uniquely philosophical way that taiji training is approached. In it, all of the attention is 
put on teaching relaxation. But this is not quite as simple as it may sound. It is actually surprisingly hard to teach relaxation in taiji, and the type of relaxation that is the ultimate goal is not simple relaxation. It takes different forms, from mental relaxation, to the hyperawareness of tension and looseness in the body, to enable higher levels of sensitivity and responsiveness, to the ability to be relaxed in otherwise difficult postures or transitions, and through to the cultivation of what they call 'sung jin', or relaxed force in the application of techniques. There are other dimensions to taiji relaxation or restfulness too. But the point is: learning it all is no simple matter. It takes a great deal of patience, commitment, and trust - trust in your teacher, trust in the investment of time and energy, faith that it will all pay off or yield dividends.

In many respects, rather than being anything like lying down and relaxing; training for this kind of relaxation is actually analogous to weight training, strength training, or bodybuilding. In weight training for strength or bodybuilding, a key principle is 'progressive resistance'. Over time you put more and more weight on the bar so that the resistance placed on the muscles progressively increases. In response to increasing demands, followed by adequate rest and nutrition, the muscles, tendons and ligaments, etc., respond - by growing stronger, often larger, more dense, and so on.

Despite appearances, training in and around taiji is similar. However instead of external resistance, there is more a kind of progressive intensification of 'rust' - a 'progressive res[t]istance', so to speak. This progressive intensification is centred on awareness of posture and breath. More refined awareness of posture goes hand in hand with more intensified relaxation. More refined and intensified awareness and control of breath leads to all sorts of unexpected health and skill consequences. On this level, I would recommend it to anyone: Taiji and qigong can become quite a remarkable combination for producing a sense of healthiness. But the idea that taiji and qigong are 'simply' all about rest or relaxation is misleading. As with any martial art, taiji requires really devoted and focused training. You have to learn how to be relaxed. You have to work hard to take control of your mind and relax it. This is not simple. It is not simple or easy to make yourself train every day when a lot of that training involves standing stock still for half an hour or more in a relatively awkward position, focusing on your breathing and posture and sensations - especially when you have jobs to do, the clock is ticking, there is work to do, and so many other demands. You have to believe in it and trust in it.

So, when it comes to the relaxation required in successfully mastering taiji, or maybe any physically and mentally demanding skill-set, to speak of 'rest' is kind of correct, yet also not quite right. I guess calmness would be the best term to apply across the board. When you're not in some sense calm, you're probably not going to be functioning at your best. This is so even though some approaches to combat training insist on forcing practitioners into extremes of adrenaline, fear, and beyond sustainable states of exhaustion. But, again, the reason for this is to get used to it, so as to learn how to manage panic and terror and exhaustion - in short, once again, so that you become, in a very particular way, calm even when operating at high levels of stress. 


\section{Zen Again}

Of course, as mentioned earlier, many East Asian martial arts are associated with lofty philosophical and cultural ideas and ideals, such as those associated with Zen Buddhism or Taoism. However, I always hesitate before accepting associations like these when it comes to East Asian martial arts 'in general'. This is for two reasons. The first is because such associations tend to come from dubious media myths and often have little historical basis. The second is because there is rarely to never any observable Zen (Chan) or Taoist dimension to many martial arts - at least no more than there is in anything else.

Despite this caveat, I still also think that it is easy (and justifiable) to see how and why something like taiji could be regarded as Taoist. Even though it is possible to refute most fantasy histories of taiji, it is undoubtedly the case that everything in its logic of training and application can be (and normally is) expressed in terms of yin and yang, plus a range of other terms deriving from Taoist cosmology and principles. But other than for internal Chinese martial arts like taiji - possibly also aikido - I really don't know how far it is possible to claim that other martial arts are 'philosophical' in the same way.

This is so even though the most popular story of the origins of 'all' kung fu states that kung fu originated as a consequence of Zen Buddhist training in the Shaolin Temple in China. Of course, this is a myth - indeed, perhaps it is an almost perfect myth. It has a grain of truth: self-defence was required at the Temple, as it was everywhere, and over time the temple gained a fearsome reputation. But as an origin myth, it is easy to refute. However, even though the myth is easy to debunk, it keeps coming back. Like a phoenix or Terminator 2, the myth of Shaolin Temple Zen training as the origin of kung fu keeps coming back, no matter how well you think you have killed it. This is why people seem compelled to associate East Asian martial arts with pacifism in general and Buddhism in particular. But my claim here is that all of this is just a 'bolt-on' to bolster the myth.

The reason I want to make such a claim is so as to suggest that mythic narratives and claims about moral or ethical codes are not what we should be looking at or thinking about when we enquire about the 'philosophy' of this or that martial art. All ethics or moralities or mores are optional extras. Rather than looking for philosophy in the 'blah blah blah' that so often surrounds martial arts, what I want to suggest is that the philosophy of a martial art is embodied, in particular ways. All martial arts and approaches to fighting are the manifestation of a kind of theory, or philosophy, or perhaps an ideology, maybe even a fantasy. The moves, the training, the sparring, all imply either a conscious or an unconscious 'theory' or 'philosophy' of all sorts of things: what violence is, what combat is, what works best, how bodies work and interact, what teaching and learning should be like, what society is like, what the place of the individual is within society, and so on. All martial arts, from the most supposedly ancient to the most avowedly modern are based on tacit, implicit or explicit premises, hypotheses, arguments, theories, fantasies or philosophies about the world, about society, and about our place and responsibilities within it. ${ }^{4}$

\footnotetext{
${ }^{4}$ Is it philosophical to say that a person has the right to defend themselves? You may say yes or no or maybe. You may even begin to wonder what it is that makes something a philosophical question at all. And that's all good. Jacques Derrida regularly suggested that the question of what is and what is not a philosophical question is
} 


\section{Philosophize-a-babble}

A friend of mine once told me that her kung fu instructor would often sit them all down and give them lectures about the philosophy of their kung fu style. Do such lectures make that kung fu style itself philosophical? I would suggest not.

We could sit down and philosophize anything - everything - that we do. But in what way does that mean that it 'is' philosophical? As I have said, I think that taiji 'is philosophical' because it actualizes Taoist principles. It is a physical expression of them (among other things). In a similar way, I think that many other martial arts are based on implicit or explicit theories about the particular kind of toughness and calmness that need to be cultivated.

Consider this. In karate they 'kiai'. Taiji has no 'kiai' - at least not in the recognisable sense of the term, as the 'spirit shout', as is associated with arts such as karate. This could be said to be an embodied dimension of the 'philosophy' underpinning each practice. In some martial arts training, what is valued and what is trained is speed, or flow, or power, or sensitivity, or athleticism, and so on. I've never made a noise in taiji - apart from maybe a yelp of pain here or there. There are lines in the so-called 'Taiji Classics' that insist that taiji should be silent. But almost every punch I have ever thrown at a pad in escrima training has been accompanied by some kind of guttural shout or grunt or hiss - expressing and intensifying the intent to smash into the target as hard as possible. So, there's something there whether you call it a philosophy, a theory or a psychological attitude to be trained and developed.

There are also principles that could (some would argue should) be trained across all martial arts, which could be called philosophical. One is 'go weak for technique'. As in: when you are training, always train as if you are weaker than your opponent. That way, you have to develop superior technique. For if it's just strength against strength, then the stronger will always win. Maybe this kind of attitude could be called almost Taoist. Or maybe it could just be called universal. Or maybe Taoist principles are indeed universal. Certainly, taiji advocates such an approach to the most refined degree.

Yet I still see no necessary Zen Buddhism in kung fu, karate, judo or jujutsu. And I actually cannot comprehend why something like taekwondo even ever makes any reference to the yin-yang symbol. For, even though many martial arts make connections to the yin-yang, I firmly believe that this is principally because the yin-yang is a cool-looking symbol. But it often has next to no functional connection with what they do. In other words, I am suggesting that the connections that are often assumed to exist between supposedly 'Eastern' martial arts and so-called 'Eastern philosophy' are both not essential and often actually garbled and convoluted. In fact, I will go further and state that these connections often owe more to mass media myths and fantasies than anything specific to the practices themselves.

But does that mean that I am saying that there are some 'truly' philosophical arts like taiji, that are therefore 'good' (because they are philosophical in my apparently preferred sense),

actually a question that is always at the heart of philosophy. So, Derrida saw everything as philosophical. (And, of course, we may add, therefore nothing as uniquely or specifically or only philosophical.) 
while there are other, maybe modern, corporate and profit-focused arts like MMA or taekwondo, that are somehow therefore 'bad' (because they are not philosophical in my apparently preferred sense)? I'm going to say 'no': I'm not saying that - for lots of reasons. More reasons than there is time or space even to gesture to here and now. Everything can be philosophised. Everything we do is the manifestation of some kind of implicit or explicit theory, outlook or philosophy. But even if something is strongly connected with a philosophy that you or I may personally prefer, this does not necessarily make such practices 'good'. Calmness does not mean good. Nor does calmness mean moral, safe, sane or superior.

\section{Madfulness Meditation}

Consider this. What is it that makes so many people think that things like yoga, taiji and qigong are somehow simply or necessarily good? I would propose that one of the main things that leads to this conclusion relates to the many regular associations made between these kinds of practices and the idea of positive mental health: Mental health, mind-body awareness, mindfulness, work/life balance, and so on.

Now, as I've already confessed, as a practitioner of taiji and qigong, on some level I really do believe in the 'positive mental health' narrative that surrounds internal martial arts and yoga. But as a practitioner of other martial arts, and also as someone who sometimes has a philosophical bent, and certainly as someone who watches YouTube, and so on, I also wonder whether sometimes such positive mental health and supposed awareness comes at a cost of positive self-delusion and a particular lack of awareness.

For instance, many (perhaps most) taiji practitioners believe in magic. Some martial artists believe you can hit someone without actually making physical contact with them, like some kind of Jedi Knight. The magic conduit for this and many other things is called qi (chi) which is an eminently magic proposition. Nonetheless, many people believe in qi. But for what reasons, on what evidence, and to what ends? Much of this may be harmless. But, at the same time, videos abound on YouTube of hapless qi and ki masters who have done things like challenging MMA and other full contact martial artists to a fight only to be battered black and blue by them. There are also embarrassing videos aplenty in which poor deluded students bounce and leap about in response to their master's touch, or gesture. Similarly, many people spend long hours of days, weeks, months, years and decades engaged in practices ranging from qigong to push hands to point sparring and so on believing that they are preparing themselves for the reality of combat. In short, there are many kinds of martial arts self-delusion, all of which I'm sure are also accompanied by many kinds of awareness and insight.

In the wider cultural/ideological realm, what are we really to make of employers offering their overworked and stressed out employees free taiji or mindfulness meditation classes? Do firms lay on such services out of the goodness of their hearts? Or might there be other agendas? We might ask the same of the state promotion of martial arts in schools across Asia: are these motivated by philosophical ideals any loftier than nationalism? And how many financial traders, speculators, yuppies and bankers have believed that they are most in touch with their own fundamental truth and reality when they are engaged in their early morning 
yoga or meditation, and not when they are speculating on futures? But perhaps at the most extreme end of things: how many sociopaths, psychopaths or misanthropes have either prepared for or dealt with their atrocious acts by meditating? (Anders Behring Breivik prepared himself for 'one of the most devastating acts of mass murder by an individual in history' on July $22^{\text {nd }} 2011$, by undertaking a long period of training in what he called 'Bushido meditation'. I will return to this.) Or, at another extreme: consider the fact that many martial artists of the late nineteenth century anti-foreigner Boxer Uprising in China believed that their 'iron shirt' kung fu training would make them impervious to bullets. In many different kinds of cases, what seems to sustain and nourish people in many martial arts activities are fantasies about tapping into or communing or connecting with something. Very often, this involves fantasies about an ancient mystical truth. The fantasy is a fantasy of something that may well never have existed. Qi and chakras and meridians may well be tenets of faith, and the internal martial arts training which focuses on moving qi through meridians may well be an exemplary exercise in supreme self-delusion.

Or it may not. Maybe you can never know something unless you try it. Or, maybe more than 'trying': maybe you can never truly know something unless you've mastered it. But maybe trying to master something like this will be the very thing that pulls you into a world of selfdelusion. Maybe this is particularly so because to try to master anything like this will always require having some kind of faith and some kind of belief. You cannot maintain qigong meditation or taiji slowness training without some element of belief, some element of faith, some element of trust in something - whether that be a teacher, or a promise of health or invincibility or longevity.

Philosophers from Kierkegaard to Derrida have reflected on the decision - the decision to do something, to try something, to make a certain move, to reach a certain conclusion and they have called it 'a moment of madness', a leap of faith, a step into the unknown, the abyss, the void. Take the blue pill or take the red pill; have faith in an idea or an argument or theory or a philosophy. Persuade yourself to stand in static meditation every day for half an hour or more. Practice forms over and over again for the rest of your life. Maybe this is the path. Or maybe you're swimming on dry land, believing it will help you to swim up a strong river; or maybe you're just playing air guitar, believing that you are turning yourself into the new Jimmy Hendrix.

What is sensible and what is not? Listening to someone or walking away? What if they claim to have all the answers, to be the experts, to know the truth? We know we should eye such people with suspicion. But what if someone told you at the outset that they were going to hold forth on something they might actually know nothing about - like how a word from a language they can't speak relates to a world of philosophy they only know in the most woefully general of ways? What would you do in that situation? What did you do in that situation? Did you trust? Or did you rust? 


\section{Philosology and Psychosophy}

Clearly, 'philosophy' and 'psychology' can shade into each other, and different interpretations of philosophy, or different philosophies, can have psychological impacts. In martial arts, as well as there being different philosophies, there are differing underlying psychological theories or beliefs that inform or even underpin different disciplines (Bowman 2014). Different styles, systems, regions and periods often manifest different discourses, theories or ideologies of what we might call martial arts psychology. All of this might be referred to as the martial artist's outlook, mindset, psyche, or subjective stance or attitude. Such outlooks or attitudes might be linked to the ethos of the training environment (García and Spencer 2014).

Of course, sometimes - as in many discourses around boxing or MMA - the dominant idea has often been that 'being a fighter' is something innate - something you are 'born with' (Spencer 2011; Wacquant 2004). This seems to be a very common claim among competitive fighters and those involved in some way with what we might call street fighting (i.e., people with some kind of connection to non-rule-bound fighting and violence, such as bouncers, for example). But my sense is that in most martial arts, 'being' - or, more precisely, 'becoming' - a fighter is conceived of in terms of some kind of notion of 'fighting spirit', and that such a 'spirit' is something that is cultivated, through what Foucault would term 'the means of correct training' (Foucault 1977, 1978). My sense is also that different martial arts - or even the 'same' martial art at different times - seek to cultivate very different 'kinds' of martial arts subject.

In my own life, I have experienced very different kinds of training ethos. Some seemed saturated with a vague sense of the inherent value of 'toughening up' (Green 2011; Downey 2007; Spencer 2011). Others focused more on having fun, competition and competitive play (O'Shea 2018). Still others put the importance of a certain psychological attitude front and centre - whether that be cultivating dispassionate calm responsive sensitivity (as in taijiquan, particularly in push-hands training), developing an explicit 'predator awareness' selfdefence mindset, or an insistence on a kind of all-out aggression, such as that which is termed 'forward thinking' in escrima concepts (Bowman 2014, 2015; Miller 2008, 2015). Some were informed by mysticism, others by hierarchy, authority and deference, and still others by camaraderie and a sense of being involved in a shared research project. Informed by this diversity of experience as well as other forms of research, I have argued before that martial arts can very often be regarded as intimately imbricated within different kinds of ideology. However, what I am proposing here is something slightly different. Unlike virtually all other studies in this realm, I am at this point less focused on the matter of the ideologies that 'go into' the discourse of a martial art, and more interested in the question of the types of subjects that 'come out' - that are produced in and by martial arts training: the type of subjective attitude, mindset, sense of identity and orientation towards the world.

Obviously, this is a two-way street - or even an incredibly complex junction. But an article by Oleg Benesch highlights what I am interested in here, in very stark terms. Benesch begins 
his article, 'Reconsidering Zen, Samurai and the Martial Arts' (Benesch 2016), with a consideration of the case of Anders Berhing Breivik, who, 'on July 22, 2011 ... committed one of the most devastating acts of mass murder by an individual in history' (1). Benesch writes:

\begin{abstract}
'Over the course of one day, he killed 77 people in and around Oslo, Norway, through a combination of a car bomb and shootings. The latter took place on the island of Utøya, where 69 people died, most of them teenagers attending an event sponsored by the Workers' Youth League. During his subsequent trial, Breivik remained outwardly unemotional as he clearly recounted the events of the day, including the dozens of methodical execution-style shootings on the island. His calmness both on the day of the murders and during the trial, shocked many observers. It was also an important factor in an attempt to declare Breivik insane, a move that he successfully resisted. Breivik himself addressed this subject at some length, crediting his supposed ability to suppress anxiety and the fear of death through concentrated practice of what he called 'bushido meditation'. He claimed to have begun this practice in 2006 to 'de-emotionalize' himself in preparation for a suicide attack. According to Breivik, his meditation was based on a combination of 'Christian prayer' and the 'bushido warrior codex'. Bushido, or 'the way of the warrior', is often portrayed as an ancient moral code followed by the Japanese samurai, although the historical evidence shows that it is largely a twentieth-century construct.' (Benesch 2016: 1)
\end{abstract}

Benesch's own interests in this matter relate to addressing the matter of many misunderstandings of the history of notions like 'samurai spirit', and the supposed connection of this spirit with Zen. As the above passage suggests, he is animated by the fact that what is 'largely a twentieth-century construct' has functioned ideologically. Benesch's project, here and elsewhere, is to set out the ways that such factually incorrect discourses have emerged, and to clarify the ways that they have functioned ideologically. However, as noted, my own interests at this point are chiefly related to what we might call the various types of psychology or pseudo-psychologies of violence and training for combat that are attendant to different kinds of martial arts pedagogy and philosophy.

But Benesch's article is extremely helpful for me here because it sets out clearly the relations between a number of elements that I contend it is important to realise are interconnected. Specifically, this is the connection between a training ethos and its theory of psychology - or, indeed, its theory of the subject - and the extent to which neither of these are 'innate' or 'necessary', but rather entirely 'cultural'. This is not 'cultural' in the sense that we often too easily use the term - as when we say 'Eastern' or 'Western', or 'American' or 'European', and so on. Rather, this is cultural in the sense of engendered, cultivated, fostered, stimulated, managed, produced, even policed, through techniques of discipline, and always informed by ideology. ${ }^{5}$

\footnotetext{
${ }^{5}$ In a study of language, argumentation, the establishment of truth and ideology, Jean François Lyotard once argued that 'to link is necessary, but how to link is contingent' (Lyotard 1988). My contention here is that both training methods and ideological outlooks are contingent, as is the manner of their linkage. The different forms that the various connections, combinations and relations take will always produce very different things.
}

Bowman, P. (2019). Mindfulness and Madness in Martial Arts Philosophy.

Journal of Martial Arts Research, 2 (1).

DOI: 10.15495/ojs_25678221_21_93 | j-o-mar.com 
Indeed, the implications of Benesch's opening reflection on the case of Breivik's 'psychology' go further than many studies of the relations between ideology and psychology might otherwise tend to go. For instance, in a very rich and suggestive passage, Benesch notes:

\begin{abstract}
'The extent to which the methodical nature of Breivik's terror attack could be ascribed to his meditation techniques, 'bushido' or otherwise, has been called into question by those who see it as another manifestation of serious mental disturbance. On the other hand, Breivik's statements regarding 'bushido meditation' have parallels with the 'Warrior Mind Training' program implemented by the US military during the Iraq War. This program claims to have its roots in 'the ancient samurai code of self-discipline', and is described as a meditation method for dealing with a host of mental issues related to combat. Both Anders Breivik and Warrior Mind Training reflect a persistent popular perception of the samurai as fighting machines who were able to suppress any fear of death through the practice of meditation techniques based in Zen Buddhism. Zen has also been linked with the Special Attack Forces (or 'Kamikaze') of the Second World War, who supposedly used meditation methods ascribed to Zen to prepare for their suicide missions.' (1)
\end{abstract}

Here, not only does Benesch reinforce my contentions about the 'cultural' dimensions of all of this, but he actually raises the stakes of my own argument by introducing the question not just of mindset but also of sanity and insanity.

Hopefully, none of us are anything like Breivik. But Breivik claims to have believed himself to have trained for his acts of unimaginably callous mass murder by following a self-styled but not entirely alien or unusual type of 'martial art' psychological training. Which raises the question: Are such martial arts ideologies themselves to be regarded as sane or insane?

Such a question, posed outside of any context or any specific case study, will hardly permit a univocal response. Such a question is based on an unacceptable generalisation at both ends. It is, to borrow a phrase from Freud, an equation between two unknowns. What is a martial arts ideology? What is sanity? Clearly, there is a lot more work to be done here before we can even formulate our question adequately. Nonetheless, I am reminded of the time a few years ago when a student of mine walked out of a film screening. The film I was showing was Ghost Dog: The Way of the Samurai (Jarmusch 1999), in which the eponymous Ghost Dog (Forrest Whittaker) is a late twentieth century black urban character who so identifies with the samurai ideology advocated in the putative samurai manual, Hagakure, that he has crafted himself as the 'retainer' of an old mafia gangster who once saved his life. Ghost Dog lives alone, trains martial arts, and undertakes assassinations whenever his 'master' requires.

The film has long raised interesting questions for me about identity construction, crosscultural interests and historical communication (Bowman 2008). But when I asked the student why she walked out of the screening she replied: Because Ghost Dog was insane. Until then, I had not actually stepped outside of the fictional world of the film to ask myself the question of Ghost Dog's sanity. The film presents him as an assassin with a fixation on samurai ideology. What does that make him? Eccentric? Mad? 
The character, Ghost Dog (Forrest Whittaker), spends a great deal of time involved in solitary martial arts training, and regularly reads the samurai text, Hagakure, as if to 'de-emotionalize' himself vis-à-vis 'death' (the Hagakure regularly reiterates the necessity of 'meditating on inevitable death'). Ghost Dog believes himself to be 'the retainer' of a mafia boss. So, to this extent, he could easily be labelled insane. Similarly, another contemporaneous film, which is more explicitly about insanity, resonates with cognate ideas. In a memorable scene in Fight Club, Brad Pitt's Tyler Durden holds down the hand of 'the Narrator' (aka 'Jack', played by Edward Norton) onto a table and gives him a serious chemical burn. All the while, Durden holds forth on the subject of experiencing the sensation in the moment and giving up on the idea of escaping from the pain, either in the form of physically running away and trying to soothe the pain or in the form of retreating to 'your cave', or - as they used to say - 'using mind over matter' to escape from the pain of the situation by visualising something else, some other situation, elsewhere.

The scene runs as follows:

Tyler: The crucial ingredient. [...] Can I see your hand please?

[Narrator gives him his hand. Tyler grasps onto it, licks his lips and kisses the back of Narrators hand]

Narrator: What is this?

[Tyler looks at him, sprinkles the lye on the narrator's hand and says]

Tyler: This is a chemical burn.

[Narrator screams in pain, staring at his hand as it begins to burn, reeling while Tyler grasps it tightly.]

Tyler: It will hurt more than you have ever been burned and you will have a scar. Narrator: What are you doing?! [screams]

Narrator Voice Over: Guided meditation worked for cancer it could work for this. [Narrator closes his eyes, cut to scene of green forest in his mind. Cut back to Tyler.] Tyler: Stay with the pain, don't shut this out.

Narrator: No, no! [screaming moving violently, trying to escape Tyler's grasp]

Tyler: Stay with the pain, don't shut this out. The first soap was made from the ashes of heroes, like the first monkey shot into space. Without pain, without sacrifice we would have nothing.

[Narrator closes his eyes again, trying to shut the pain out, trying to be calm]

Narrator Voice Over: I tried not to think of the words searing flesh.

Tyler: Stop it! This is your pain. This is your burning hand. It's right here.

Narrator: I'm going to my cave, I'm going to my cave, I'm going to find my power animal. [sobbing]

Tyler: No! Don't deal with it the way those dead people do. Come On!

Narrator: I get the point okay please!

Tyler: No, what you're feeling is premature enlightenment.

[Narrator closes his eyes, cut to his mind's eye in his cave. Cut back to Tyler. Tyler hits Narrator across his face]

Tyler: This is the greatest moment of your life and you're off somewhere missing it.

Narrator: I am not! [sobbing and grunting in pain] 
Tyler: Shut up. Our fathers were our models for god. If our fathers bailed what does that tell you about god?

Narrator: [grunts, eyes closed still fighting the pain]

[Tyler hits narrator across the face again. Narrator still reeling, moves his hand, attempting to reach for sink, for water. Tyler holds fast.]

Tyler: Listen to me. You can run water over your hand to make it worse, or, look at me. [Their eyes meet] Or you can use vinegar to neutralize the burn.

Narrator: Please let me have it!! Please!! [sobbing]

Tyler: First you have to give up. First you have to know, not fear, know that one day you are going to die.

Narrator: You don't know how this feels!! [angrily, rage in his eyes looking at Tyler] [Tyler stares back at him and lifts up his right hand to reveal a massive scar on the back of it.]

Tyler: It's only after we've lost everything that we're free to do anything.

Narrator: Okay. [still painful look on his face but accepting]

[Tyler slowly lets go of narrator's hand finally where the flesh is melting, fizzling, smoking and burning. Narrator stares intently at his hand. Holding it out in front of himself on his own, feeling it. Not trying to run from it or trying to minimize the pain somehow. Tyler then reaches for a bottle of vinegar and dumps it on Narrator's outreached hand. Narrator, with the final relief of the pain clenches his hand towards his chest and drops to the ground. Tyler looks down at him.]

Tyler: Congratulations, you are one step closer to hitting bottom. (Ryan, 2009)

This moment of madness, in a film that is arguably about madness in multiple ways and on multiple levels, makes an unusual reference to mindfulness. This takes the specific form of the potential connections between this act, its rationale, and the kind of Zen-Samurai-madness-martial mindset that Benesch focuses on.

Quite unlike the therapy culture that 'Jack' has become immersed in at the start of the film, in which people are regularly enjoined to visit their 'caves', find their 'power animal', let their feelings out, and so on, Durden insists on the necessity of facing up to, looking directly at, and surrendering to the intensity of the physical experience. Durden will not allow Jack to run or to change the situation until he 'gives up' and stops trying to escape. He asks him to accept the inevitability of death, and adds, at the end, 'it's only after we've lost everything that we're free to do anything'.

Immediately after this scene, we see Jack in his office, being confronted by his boss, brandishing an incriminating copy of the rules of Fight Club that he has retrieved from a photocopier. In response to the rhetorical question of what Jack thinks he should do when presented with a situation like this, Jack suggests that his boss should be very, very afraid, as the kind of person who writes material like that is highly likely to be the kind of person who might just snap and stalk through the building with an assault rifle, wreaking havoc and mass murder.

Is it significant that these two 1999 films seem to connect explicitly what Benesch (following the US military) calls the 'warrior mind' with a kind of Zen-informed martial training (the

Bowman, P. (2019). Mindfulness and Madness in Martial Arts Philosophy.

Journal of Martial Arts Research, 2 (1).

DOI: 10.15495/ojs_25678221_21_93 | j-o-mar.com 
'meditation on inevitable death' that Ghost Dog reads from the Hagakure)? Certainly, these two filmic texts can be read side by side in terms of Benesch's connection of the chilling approach of Breivik to very real mass murder and my former student's damning statement that she could not sit through Ghost Dog because the main character was 'mad'. From this position, there is much that could be thought and said about Fight Club. Certainly, 'Jack' is technically insane. The film makes clear that he is hallucinating the very existence of Tyler Durden and quite probably the existence of Marla too. Maybe he's hallucinating all of it. But I also find the film to be potentially connected with debates in and around martial arts studies and social psychology in numerous ways.

I have written about much of this before. I have written about the ways that the spectre of Bruce Lee informs the imaginary ultimate male, Tyler Durden (Bowman 2010). I have reflected on the relations between Fight Club and what I called the 'fight-club-ization' that took place in and around martial arts after the televisual explosion of the UFC and the emergence of MMA in its wake (Bowman 2013). And so on. But here, thanks to Benesch's provocative work on the supposed connections between the 'warrior mind' and something akin to 'Zen' bushido training, I want to reflect on the treatment within Fight Club of what we might call its 'moment of mindfulness' ${ }^{6}$

It seems important to note that Fight Club makes a clear distinction between what Durden subjects Jack to and what Jack has hitherto experienced in his earlier addiction to therapy culture. At the start of the film, Jack has been suffering from insomnia and has pleaded with medical practitioners for medication. When drugs have not been forthcoming, he takes the advice of one doctor and gone to see 'what real pain is', by attending a testicular cancer support group. Being forced to 'let it all out' in the group, Jack has been cajoled into a situation where sobbing is mandatory, and subsequently he has found himself able to sleep at nights. Nonetheless, his interest in support groups becomes an obsession and he becomes addicted to therapy culture.

The appearance of 'another faker' (Marla) impedes his ability to get satisfaction from therapy groups, and it is only after Tyler Durden appears and drags him away from all mainstream forms of modern social life and culture, especially the creature comforts afforded by consumerism, that Jack moves from therapy culture and towards fighting as therapy.

I have written about 'fighting as therapy' elsewhere (Bowman, 2017), so I will try not to repeat any of that here. What I am interested in at this point is less the fighting in Fight Club and more the moment of mindfulness, where Durden makes Jack focus on the pain of a chemical burn, give in to it, give up, and accept the inevitability of death.

In response to the pain and his inability to escape Durden's grip, we see Jack trying not to think of the words 'searing' and 'pain', which he is trying to escape from. Soon he jumps to

\footnotetext{
${ }^{6}$ Some readers may notice in the phrase 'the moment of mindfulness' an allusion to Kierkegaard's famous line, 'the decision is a moment of madness'. This is fortuitous, or maybe just fertile. Certainly, Jacques Derrida picked up this idea and ran with it into some of his most stimulating and - I think - important work (Derrida 2001, 1996).
}

Bowman, P. (2019). Mindfulness and Madness in Martial Arts Philosophy. 
the entrance to his 'cave' - a place he has learned to go to during therapy sessions. Durden shouts him back into the present. Then an image of beautiful trees in a forest flashes up. But Durden keeps shouting at Jack and drawing him back into the present moment. The images of 'his cave' and the very easily recognisable - indeed clichéd - image of 'a peaceful place' (dappled light through trees) - disappear when Durden shouts at him.

So, in this film too, at this moment, the 'warrior mind' emerges through 'reflection on inevitable death', 'meditating on inevitable death' and living one's life 'as dead', as if already dead.

It is very shortly after this that the first recruit to Tyler's paramilitary cult turns up and stands on the doorstep of Tyler and Jack's house, waiting for permission to enter and to begin 'training'. The visual representation here is modern and military. But those immersed in the mythology of Eastern martial arts will recognise the scenario as the first test of potential students seeking to be taught by a given master. Shortly after this scene, of course, we see the production of a small militia, which begins 'Project Mayhem'.

What is going on in all of this? The film certainly involves both meta and micro critiques of many things: consumerism, therapy culture, the supposed vacuity of much work and daily life, the men's movement, and masculinity, most prominently. But what are we to make of the implicit connection between the film's championing of living in the moment, feeling it, accepting it, not retreating from pain, and so on, and several species of insanity? Is this all 'just in the film', or might there indeed be challenging lines of enquiry between mindfulness and madness? 


\section{References}

Benesch, Oleg. 2016. 'Reconsidering Zen, Samurai, and the Martial Arts'. The Asia-Pacific Journal 14 (17): 1-23. http://apjjf.org/2016/17/Benesch.html.

Bowman, Paul. 2008. Deconstructing Popular Culture. Palgrave Macmillan.

---. 2010. Theorizing Bruce Lee: Film-Fantasy-Fighting-Philosophy. Rodopi.

---. 2013. Beyond Bruce Lee: Chasing the Dragon through Film, Philosophy, and Popular Culture. Columbia University Press.

---. 2014. 'Instituting Reality in Martial Arts Practice'. JOMEC Journal, 1-24.

---. 2015. Martial Arts Studies: Disrupting Disciplinary Boundaries. London: Rowman and Littlefield International.

---. 2017. Mythologies of Martial Arts. London: Rowman \& Littlefield International.

Derrida, Jacques. 1996. 'Remarks on Deconstruction and Pragmatism'. In Deconstruction and Pragmatism, edited by Chantal Mouffe. London: Routledge.

---. 2001. Writing and difference. Translated by Alan Bass. London: Routledge.

Downey, Greg. 2007. 'Producing Pain: Techniques and Technologies in No-Holds-Barred Fighting'. Social Studies of Science 2007 37: 20137 (2): 201-26.

Foucault, Michel. 1977. Discipline and Punish: The Birth of the Prison. New York: Pantheon Books.

---. 1978. The History of Sexuality, Volume 1. London: Penguin.

Frank, Adam. 2006. Taijiquan and the Search for the Little Old Chinese Man: Understanding Identity Through Martial Arts. Palgrave Macmillan.

García, Raúl Sánchez, and Dale C. Spencer. 2014. Fighting Scholars: Habitus and Ethnographies of Martial Arts and Combat Sports. Anthem Press.

Green, Kyle. 2011. 'It Hurts So It Must Be Real: Sensing the Seduction of Mixed Martial Arts'. Social \& Cultural Geography 12 (4): 377-96.

Jarmusch, Jim. 1999. Ghost Dog: The Way of the Samurai. Artisan Entertainment.

Miller, Rory. 2008. Meditations on Violence : A Comparison of Martial Arts Training \& Real World Violence. Boston, Mass.: YMAA.

---. 2015. Conflict Communication (ConCom): A New Paradigm in Conscious Communication. Ymaa Publication Center.

O’Shea, Janet. 2018. Risk, Failure, Play: What Dance Reveals about Martial Arts Training. New York: Oxford University Press.

Rancière, Jacques. 1991. The Ignorant Schoolmaster: Five Lessons in Intellectual Emancipation. Stanford: Stanford University Press.

Ryan, Blaise. 2009. 'Fight Club Quote: “Its Only after We've Lost Everything That We're Free to Do Anything”'. BlaiseRyan.Com (blog). 8 January 2009. https: / / blaiseryan.wordpress.com/2009/01/08/fight-club-quote\%e2\%80\%9cits-only-after-we\%e2\%80\%99ve-lost-everything-that-we\%e2\%80\%99re-free-to-do-anything\%e2\%80\%9d/.

Spencer, Dale. 2011. Ultimate Fighting and Embodiment: Violence, Gender and Mixed Martial Arts. London and New York: Routledge.

Wacquant, Löic. 2004. Body and Soul: Notebooks of an Apprentice Boxer. Oxford; New York: Oxford University Press.

Wile, Douglas. 2015. 'Book Review of: The Creation of Wing Chun: A Social History of the Southern Chinese Martial Arts. 2015. Benjamin Judkins and Jon Nielson. State University of New York Press'. Martial Arts Studies 1 (1): 83-85. https://doi.org/10.18573/j.2015.10021. 